ISSN: 2378-7031

Volume 6, Issue 1, 1-10 Pages

\title{
Mitigating White Invisibility through Intentional Reflective Practice
}

\author{
Dr. Pamela Hampton-Garland, Dr. Morris Thomas \\ Division of Education, Health, \& Social Work, College of Arts \& Sciences, University of the District of Columbia, \\ USA \\ Center for the Advancement of Learning, Learning Resources Division, University of the District of Columbia, USA \\ Corresponding author: Dr. Morris Thomas \\ morris.thomas@udc.edu
}

\begin{abstract}
White invisibility involves the notion that whites do not have to be noticed. Creating a society where there are people and then people of color. This can lead to several issues, particularly as it pertains to educating adults. Adult Education is grounded in Andragogy, which includes educating all adult learners. Making any learner invisible does a disservice for all parties involved. In this paper we will highlight how an Adult Education program addresses this issue by including courses in its curriculum that focuses on English Speakers of Other Languages, Special Education in Adult Education, and Adult Development Learning and Motivation where the learners in this setting are exposed to differences not only hinged in marginalization and hierarchy but through Culture \& Context course learners understand experientially how to build community by expanding their perspectives.
\end{abstract}

Key words: Adult Education, Adult Learning, Reflective Practice, White Invisibility

\section{INTRODUCTION}

\section{White Invisibility}

According to Sue (2006) white invisibility involves the notion that whites do not have to be noticed. Creating a society where there are people and then people of color can lead to issues, particularly as it pertains to educating adults. Adult Education is grounded in andragogy, which includes providing educational learning experiences that accommodates all adult learners. Andragogy is the science and art of helping Adults learn (Merriam \& Bierema, 2014). In order to help one learn, the environment in which the learning takes place must possess suitable conditions (Thomas, Harris, \& King-Berry, 2016). Making any learner invisible does a disservice for all parties involved and impedes the creation of the environment necessary to foster learner achievement. This paper will highlight the intentional reflective practices implemented by one adult education academic program designer that helped mitigate white invisibility for the learners in that program. Moreover, this paper will demonstrate how being intentional when developing an academic program improves one's ability to make all students visible.

In this context intentional reflective practice involved creating a program of study that serves adult learners without the inherent bias of "Whiteness" as normative culture. When Whiteness is viewed as the normative culture this presents the idea that people who identify or are identified as White do not belong to a racial group (Knowles \& Peng, 2005). Removing white people from a race or inferring they are "nonracial" only perpetuates White Invisibility (Ware \& Back, 2001). Moreover, when Whiteness is the dominant or the norm in society, this concept infers that 
comparatively, other groups are not the norm, thus abnormal (Garner, 2006). If an individual learner or groups of leaners are represented as abnormal, this establishes an inequitable foundation (Lowery, Chow, Knowles, \& Unzueta, 2012). According to Hartigan (1997) the notion of Race is categorized as the difference or deviance from the social norm.

According to Knowles \& Peng (2005) it is important to note that White Invisibility creates a barrier for Whites in the framework of race and how they navigate racially diverse environments. The Adult Education program in this paper sits in the context of a Historically Black University. Approximately $60 \%$ of the learners in this program are African American, therefore it is important to understand the plight of this group particularly due to their unique history within American higher education. African Americans have struggled to attain higher education since before Abraham Lincoln signed the Emancipation Proclamation in 1863 (Thomas \& Hilton, 2016). According to the Charles S. Pierce Society (2003), one of the major struggles to attain higher education, W.E.B. Dubois called "double consciousness". Double consciousness involves the perception of constantly looking at one's self through the lens of others. In this context, whites, which further perpetuates white invisibility. White invisibility has been met with resistance since the $20^{\text {th }}$ century until now. According to Biondi (2012), black students challenged fundamental tenets of American higher education, demanding that the learning environments and experiences be more inclusive with how and whom they serve. It is important to note that it was and remains important to resist and/or mitigate white invisibility because the notion of invisibility does not constitute innocence.

According to Kendi (2018), there has been intentional efforts to promote Whiteness. Kendi refers to the people who pushed these efforts as "Assimilationists." Considering that concerted efforts have been in place to create and maintain a normative culture that excludes certain groups of students has proven problematic in the landscape of higher education. Thus, making mitigating white invisibility essential to provide a more equitable learning experience. The fore mentioned barriers create a blind spot for Whites to process the racial reality and experiences of "the others." The embodied capital that stems from this blind spot also reaffirms and normalizes Whiteness as the standard by which all others must strive, at the demise of their personal standards or achievement goals (Hampton-Garland, Cooke, \& Sechrest-Ehrhardt, (2017). Whites who embody this framework, by not having a general awareness of other people with whom they insensitively interact also exacerbate "the others" ill treatment. The invisibility results in the creation of more space or difference between Whites and "the others" (Lowery, Chow, Knowles, \& Unzueta, 2012).

Whiteness, for many Whites, is defined not within a specific race but rather as a nationality.

Whites are Americans; others are only racial subgroups of that American identity (Hartman, 2004). As it pertains to this paper, this is problematic if a program of study is centered around or developed to cater to the "normal" or dominant adult learner group. The focus on the adult learners through such a lens creates an automatic marginalization for learners not belonging to this group. Therefore, it is essential that programs are developed with the capacity to provide comprehensive learning experiences that take into consideration that all learners are individuals and should be served equitably.

\section{Intentional Reflective Practice}

Developing programs that provide comprehensive learning experiences will not happen automatically. Creating learning experiences that are equitable and beneficial takes intentionality and reflection. Since this paper is focused on an Adult Education program, it was appropriate to employ an Adult Learning reflective model. Kolb's (1974) Adult Learning Reflective model is an experiential learning model to provide a framework to demonstrate how intentional reflective practice can be implemented. 
Kolb (1974) views learning as an integrated process with each of the cycles being mutually supportive of and feeding into the next (see Fig. 1). This model captures the essence of the logic model that many adults naturally use to evaluate and maximize learning.

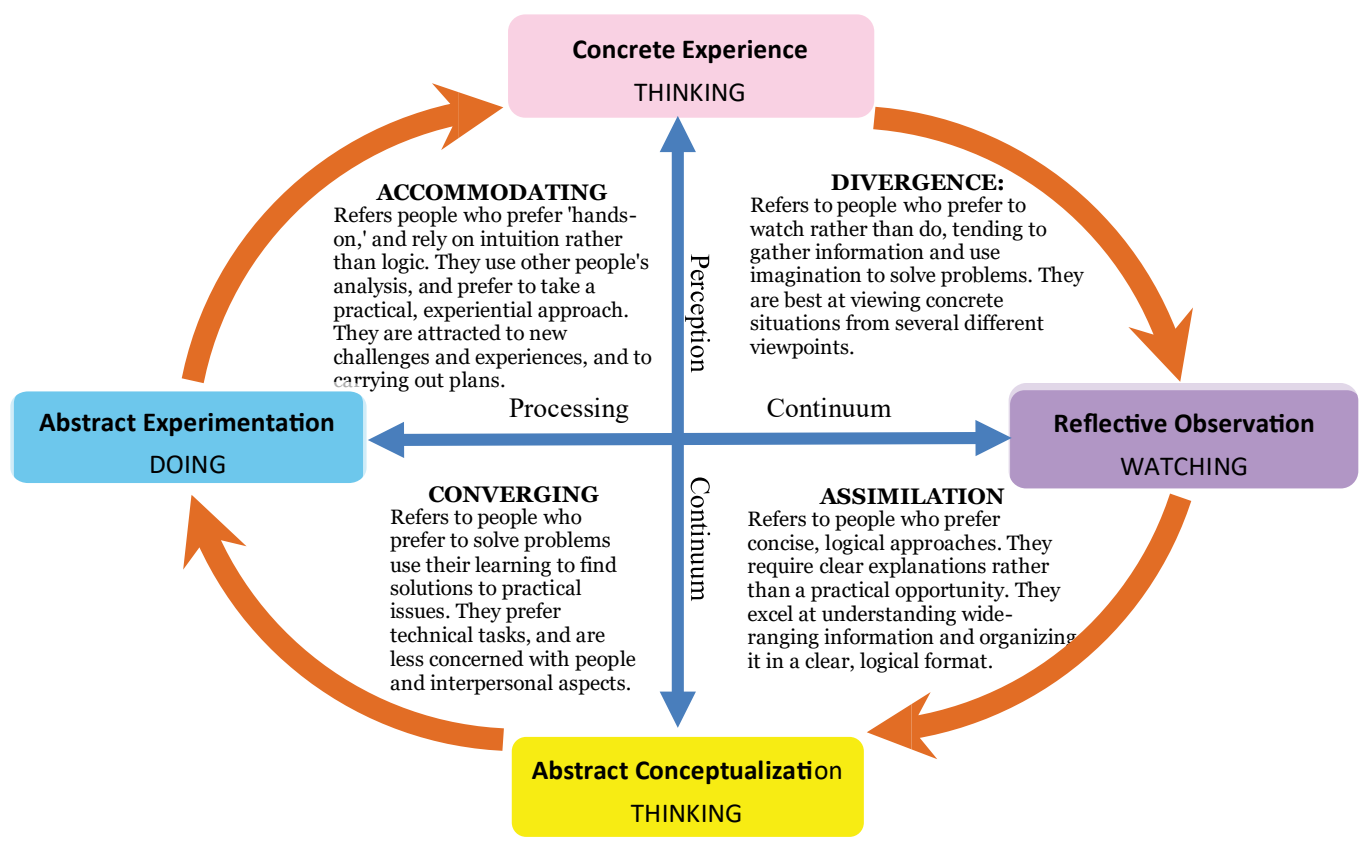

Figure 1 Kolb's Experiential Learning Cycle (1974)

Kolb's model is permissive in that it is possible to enter the cycle at any stage and follow it through its logical sequence. However, effective learning only occurs when a learner can execute all four stages of the model. Therefore, no one stage of the cycle is effective as a learning procedure on its own. The term effective is defined from a comprehensive understanding rather than a minimal awareness. Effective for Kolb is at the higher stages of Bloom's Taxonomy (1956) where synthesis is evidence of comprehension and usability across differing platforms.

According to Kolb's Experiential Learning: Experience as the Source of Learning \& Development (1984), he outlines the four stages of development. The four stages are Diverging, Assimilating, Converging \& Accommodating. Finally, Kolb recognizes the four stages of development and where and how they appear as one cycles through the process of learning along the axis. Kolb understood that individuals would likely enter the cycle where their natural learning tendency would suggest i.e. quadrant represented by the converging stage where people with a high preference for problem solving abstract experimentation (doing) and abstract conceptualization (thinking) methods meet; but stressed the fact that to fully master learning one must successfully complete the cycle. Using this approach, the Adult Education program at UDC has and continues to mitigate white invisibility by continually cycling through Kolb's Experiential Learning Cycle. Prior to understanding the program, it is critical to understand the program's context.

\section{University of the District of Columbia Composition}

The University of the District of Columbia (UDC) has undergone many transitions throughout its history. Initially UDC founded as The School for Colored Girls, by Myrtilla Miner in 1851 (University of the District of Columbia, 2019). Later the name would become the Miner Normal School. There was also the Wilson Normal School, for white girls. In 1929, Congress enacted a stature that converted both normal schools into four-year teacher colleges. The 
names of the institutions change again, becoming Miner Teachers College and Wilson Teachers College. It is important to note both institutions because they eventually merged as a result of the U.S. Supreme Court school desegregation decision, Brown v. Board of Education in 1954.

Subsequently in 1955 the fore mentioned teacher colleges merged to become the District of Columbia Teachers College. Over the next ten years, District of Columbia's residents petitioned for more higher education offerings to provide preparation for other careers than teaching. In 1966, Congress enacted the District of Columbia Public Education Act, which established Federal City College and Washington Technical Institute. Despite the establishment of the Federal City College and Washington Technical Institute, the District residents continues to advocate for a comprehensive university. In 1976, the City Council authorized the consolidation of the three schools (the District of Columbia Teachers College, Federal City College and Washington Technical Institute) creating the University of the District of Columbia. In 1977, under President Carter's leadership, UDC began consolidating its academic programs. These efforts culminated in the establishment of five colleges: Business and Public Management; Education and Human Ecology; Liberal and Fine Arts; Life Sciences; Physical Science, Engineering, and Technology; and University College and Continuing Education.

UDC continues to transform itself over time to meet the changing needs of its students and the community. The University currently offers 81 undergraduate and graduate academic degree programs through the following colleges and schools: College of Agriculture, Urban Sustainability and Environmental Sciences (CAUSES); College of Arts and Sciences (CAS); School of Business and Public Administration (SBPA); School of Engineering and Applied Sciences (SEAS); the Community College and David A. Clarke School of Law(University of the District of Columbia, 2019).

The current mission, "Embracing its essence as a public historically black urban-focused land- grant university in the nation's capital, UDC is dedicated to serving the needs of the community of the District of Columbia, and producing lifelong learners who are transformative leaders in the workforce, government, nonprofit sectors and beyond." The community that UDC serves demographically includes $48.3 \%$ African Americans, 40.4\% Caucasians, $4.5 \%$ other race, 3.6\% Asian, 2.8\% two or more races, and .3\% Native Americans/Native Alaskans (U.S. Census Bureau, 2017). Additionally, the District of Columbia's 68 square miles boast $\sim 702,000$ residents, with 72,000 (or $\sim 10 \%$ ) of those ages 25 and older lacking high school credentials (U.S. Census Data, 2017). Likewise, slightly more than thirtyone percent ( 3500) of District of Columbia's Public Schools (DCPS) students dropped out of school during the 2017/2018 academic year (DCPS Data, 2018).

According to the 2017-2018 UDC Factbook, this mission serves nearly five thousand learners by providing eightytwo-degree programs. The average age of UDC learners is 29.4 with the enrollment by ethnicity is American Indian $(0 \%)$, Asian (4\%), Black (60\%), Hispanic (11\%), White (8\%), \& Not State (17\%). According to the 2018 UDC Factsheet, nearly $(10 \%)$ of the learner population is composed of international students, predominately from the Middle East (University of the District of Columbia, 2019). Specifically, students enrolled in the adult education program at UDC are 58\% African American, 22\% Caucasian, 12\% African, and, $8 \%$ other.

Specifically, the demographics of the Adult Education participants at UDC during the past five cohorts totaling 85+ students comprised of 58\% African American, 22\% Caucasian, 12\% African, and, $8 \%$ other. The learners in this program include a variety of ethnic and religious, $12 \%$ identify as Africans from the Continent of Africa, and $2 \%$ Hispanic, and 6\% are from Jamaica, India, Latin America. As is clearly evidenced by the fore mentioned data, diversity is present in the graduate adult education program in the only public higher education institution located in the District of Columbia.

\section{Adult Education Program at UDC}

Considering previously highlighted data, the Office of the State Superintendent of Education recognized the need for 
highly qualified and licensed adult educators with specialized skills. The skills desired were those that taught learners to facilitate learning using andragogical rather than pedagogical methodologies. Targeted mastery in Adult Learning Theory and Methodology where reflective practice and self-concept are deliberately woven throughout the curriculum. Resulting in a program where the curriculum embodies and embraces otherness as the ideal through the use of learning plans, self-assessments, formal assessments and culturally relevant experiential learning engagement expectations that intentionally cause cognitive dissonance, as it is a conduit to meaningfully open dialogue and discourse that challenges embodied understandings and debunks the perceptions of normal vs. abnormal. The previously mentioned design of this program is a result of intentional practice. The intentionality of the programmatic design is a direct result of being reflective. The intentional reflective practice allowed for the program developer to consider the diverse demographic of the institution and the Adult Education program participants. In the next sections, the program developer will discuss in detail how the Adult Education program's evolution. Through this discussion, the intentional reflective practice becomes evident, more importantly a program is developed that does not perpetuate white invisibility.

\section{Beginning the Journey}

August 2014, I (Dr. Pamela Hampton-Garland) arrived at the University of the District of Columbia (UDC) as an assistant professor responsible for reviving the certificate and master's degree programs in Adult Education after a ten-year hiatus. I arrived to a reinstatement plan, but no syllabi, or actual curriculum in place. Being unfamiliar with the University of the District of Columbia or the lack of a plan did not diminish my excitement. Quite the reverse, I recognized that the blank canvas of the adult education plan that offered a reinstatement wish list was an opportunity to create a program that would positively impact adult education in the District of Columbia.

I was greeted by a cohort of fourteen learners who had taught many years in various Adult Basic Education (ABE), Graduate Equivalency Degree (GED), Teaching English as a Second Language (TESOL), and Workforce Development (WFD) courses. The learners were motivated to become a part of the first cohort of learners to be certified and licensed as Adult Educators by the Office of the State Superintendent of Education (OSSE). Th learners were passionate, skilled, culturally sensitive to their learners needs, and diverse in both who they served and who they were. Many had master's degrees and several had terminal degrees; however, this program was to help transform them from teachers using pedagogy to facilitators using andragogy in their classroom environments. This audience was slightly different from the learners I worked with during my six years of facilitating less experienced learners in adult education graduate courses at NC A\&T state university. Whereas the learners enrolled in the UDC program were already teaching or operating in the adult education world of ABE, GED, TESOL, and WFD and were intentional about enhancing their capacities to better serve their population of learners. They were not seeking new careers but new approaches to operating in their current practices and professions.

\section{Journey to the Next Level - Self-Discovery}

To help learners enrolling in this program achieve their goals to become impactful and master adult educators, each course employs a scaffolding approach with self-concept assessments. These assessments are used throughout the program to deepen learners' knowledge of the self. Intentional reflective practice to mitigate white invisibility requires that facilitators know themselves and understand the relevance of their norms to help them limit superimposing their plans on their learners. The six core courses that progressively deepen the learners' ability to critically assess their understanding and enhance their capacity to support their learners; followed by an intensely self-directed experiential practicum and reflective seminar course. The Learning Plan is the bedrock of the Self-Concept Influenced Approach to Reflective Practice (SCIARP). All learners entering the program begin dismantling the cloak of self-absorption through 
the learning plan where learners are required to seriously reflect on their current knowledge and what they have learned as adult educators up to the point they arrived in this program. Learners rate themselves on their understanding of each course a proficiency scale following which they develop their learning plan by considering the learning outcomes for each course. This self-assessment places the learner in the driving seat for what they want to learn from each course based upon a set of pre-determined and university approved learning outcomes. Once learners have determined what outcomes from each course are important to helping them further their personal goals, learners must determine the timeframe for which they will achieve the said outcomes, and what evidence will confirm their achievement based on their specific key performance indicators will ratify their mastery of the objective. The learning plan is a task that most learners struggle with during the first two courses until they begin noticing they indeed are reaching their goals. The plan is revisited two times each semester by the learners' academic advisor and is an ongoing practice during each course. One additional key requirement of the learning plan is that learners must determine which learning strategy they will use to master each learning objective. This is where the reflective learning (SCIARP) gets its wings.

Self-Concept is the self that one has constructed for oneself based upon their beliefs of the self and the affirmations of those beliefs by others. It is my belief that the idea of self-concept is fluid and reflexive in nature based upon the intentional attention given to adjusting or modifying oneself. However, most instances a persons' self-concept is established and concretized for eternity; thus, unchallenged or questioned. To mitigate philosophies of hegemonic, paternalistic white invisibility the self-concept must be intentionally placed under the microscope for the self. To this end all students in the first foundational course take several self-assessments including learning style assessments such as Howard Gardener's Multiple Intelligence and Kolb's learning styles. To delve deeper into who learners are as leaders they take several professionally delivered assessments including the DiSC Leadership assessment and Gallup Strength's assessment where they are coached on both assessments as a way for them to understand who they are and how they lead others and comport to the world around them.

Learners also take the Motivator's profile and the Emotional Quotient assessments to understand their intrinsic motivations and their level of emotional intelligence as measures to support mastery of their goals. Finally, they complete self-assessments such as the Philosophy of Adult Education Indicator, and the Principles of Adult Learning Scales which help learners gauge their current philosophy and determining whether they are learner or teacher centered in using their philosophy. These tools fill our learners' self-concept toolbox by mid semester of their first course and first year in the program allowing the hard work to begin.

\section{Journey to the Path of Intentional Self-Reflection}

Each semester learners encounter different courses where they must incorporate the self that they now have labels for into the learning plan (see Table 1 Self-Concept Influenced Approach to Reflective Practice (SCIARP) Adult Education Learning Plan) as strategic tools to build the learner and andragogical practitioner they have determined they want to become. Although a similar tool existed at the start of the program, through intentional reflective practice I have refined the tool into what you see below. With this tool learners become acutely aware of their biases, perceptions, ways of knowing, strengths, and areas where imminent improved skills are needed to succeed as adult educators. The below learning plan is an example of how this program mitigates white invisibility as it shows what a student might create as a self-concept guide to help them reach their mastery of a learning objective that is meaningful in the work they seek to master. This work is completed by every learner in the program in each course. 
Table 1Self-Concept Influenced Approach to Reflective Practice (SCIARP)Adult Education Learning Plan

\section{Dr. Pamela Hampton-Garland}

Instructions: Read each criterion carefully

1. Reflect on your learning experience

2. Rate yourself on your current proficiency for each course now

3. Develop your individual learning plan with consideration of course learning outcomes

Definition of Terms

Learning Objectives: Students choose one learning objective from each of the three course modules that they want to master.

Learning Strategies: Students use the outcomes from each assessment taken (Gallup's Strengths Assessment, DiSC's Leadership Assessment, Motivation Profile, Emotional Quotient, Kolb's, Gardener's and VARK learning styles, Principals of Adult Learning Scale and Philosophy of Adult

Education Indicator) to develop strategies on how to gain mastery of the objectives they have chosen.

Current Level of Proficiency: Students determine what they believe is their current level of proficiency with the objective as a tool to establish a starting point.

$\mathrm{P}=$ Proficient; Or I= Intermediate; $\mathrm{N}=$ Needs improvement- Very little

Evidence of Achievement: Students must develop an evidence based outcome to verify and demonstrate proficiency with the objective; i.e. completion of a viable curriculum to demonstrate ability to develop and andragogically designed workshop.

Target Date: The Date you will complete course and objectives

Key Performance Indicators: Demonstration of your success at reaching your target as evidenced: i.e. by facilitating the workshop to adults where the intended goals were achieved and the participants assessments reflected that they reached the higher levels of Bloom's Taxonomy i.e. application, analyzing, evaluating and synthesis/creating

\begin{tabular}{c|l|l|l|l|c||}
\hline $\begin{array}{c}\text { Learning Objectives: } \\
\text { What do you want to } \\
\text { accomplish? }\end{array}$ & Learning Strategies & $\begin{array}{l}\text { Current Level } \\
\text { of Proficiency }\end{array}$ & $\begin{array}{c}\text { Evidence of } \\
\text { Achievement }\end{array}$ & Target Date & $\begin{array}{c}\text { Key Performance } \\
\text { Indicators }\end{array}$ \\
\hline $\begin{array}{c}\text { Ex: Develop an effective } \\
\text { curriculum to teach adult } \\
\text { facilitators how to } \\
\text { effectively facilitate } \\
\text { learning to adults with } \\
\text { dyslexia. }\end{array}$ & $\begin{array}{l}\text { GS: Using my learner } \\
\text { strength, I will study } \\
\text { strategies for teaching } \\
\text { adults with Dyslexia. } \\
\text { DiSC: as a Di Leader I } \\
\text { will use my } \\
\text { Dominance and } \\
\text { Influencing abilities to } \\
\text { ensure that I ask } \\
\text { questions that will help } \\
\text { me achieve my goals } \\
\text { a. }\end{array}$ & $\begin{array}{l}\text { I am at } \\
\text { Proficient with } \\
\text { curriculum } \\
\text { development; } \\
\text { but at Needs } \\
\text { Improvement } \\
\text { with } \\
\text { understanding } \\
\text { Dyslexia }\end{array}$ & $\begin{array}{l}\text { Completion of a } \\
\text { viable curriculum to } \\
\text { demonstrate ability } \\
\text { to develop and } \\
\text { andragogically } \\
\text { designed dyslexia } \\
\text { workshop }\end{array}$ & $12 / 31 / 2019$ & $\begin{array}{c}\text { Facilitating the workshop } \\
\text { to ABE adult educator } \\
\text { and having them achieve } \\
\text { the intended goals as } \\
\text { evidenced by their } \\
\text { assessment outcomes and } \\
\text { as reflected in their ability } \\
\text { to demonstrate learning at } \\
\text { the higher levels of } \\
\text { Bloom's Taxonomy i.e. } \\
\text { application, analyzing, } \\
\text { evaluating and } \\
\text { synthesis/creating }\end{array}$ \\
\hline
\end{tabular}

Following the foundational toolbox building, learners begin to construct a bridge from novice to proficient/competent. Each course in the graduate adult education course incorporates a community service component where learners implement learned information as a way to determine where on Bloom's Taxonomy they are and provide opportunities to rise through to the levels of applying, analyzing evaluating, and ultimately to creating. The following courses specifically challenge the ideology of white invisibility as the normative world that all others are measured against. Teaching English Speakers of Other Languages (TESOL) exposes our learners to engineers, doctors, educators, and other professionals who have made the United States their home and desire to enhance their citizenship by mastering the English language. In this course learners are placed in environments where they become the other and must become accustomed to the languages and ways of knowing of foreign speakers from diverse cultural backgrounds. Learners acknowledge their lack of comfort and yet are intrigued by their facilitator's knowledge, wisdom, and capacity to strive for greatness.

\section{Journey through Course Application}

Additionally, in the Transitioning Adults with Learning Differences course, our learners work with learners who have struggled in traditional learning environments due to diagnosed and undiagnosed learning differences. These populations of learners oftentimes have been clearly made aware of the fact that they are not "normal" and have 
fought to prove that they can learn. This is evident in the fact that they walk into our agencies seeking to pursue education that improves their quality of life. The fact that learners from all cultural backgrounds suffer from learning differences enter our agencies is not unusual, however what most have in common are their socioeconomic standing. Children and adults from low income and marginalized communities often attend schools where their differences are not addressed with positive solutions; thus, when they become adults strive to pursue education the goal is not reach the level of the European, middle class white man, but to be able to balance a budget.

Through the program's courses and others, we place our learners in learning environments where normal is determined by each person participating in the program. However, in our Culture and Context course I place a microscope on the heartbeat of mitigating white invisibility. Learners in this course as in all others are subjected to several assessments that explore their levels of culture competence in addition to embedding within their Learning Plan how they will work on mitigating white invisibility within their courses and with their learners. This is done through our course book, and four works that provide insight into urban, rural, middle eastern, and Latin American cultures. Learners' write five essays: one per each non-fictional novel, and a final comparative analysis using two theoretical frameworks from there textbook. Each of these works place our readers into places of discomfort, that challenges their social and cultural awareness of the world around them and theoretically forces them to assess the cognitive dissonance that often leave my learners critically reflecting their personal values and prejudices.

\section{Application through Experience}

Finally, each academic year learners have an opportunity to study abroad. The study abroad experience is intended to expand their experiences and build bridges through meaningful experiential methods. Learners have traveled to London, Paris, Cuba, and in the upcoming year will travel to Recife, Brazil to understand more about Paulo Freire's work. Developing this process has been arduous as there is always something that can be improved. Each semester I conduct learner assessments, self-assessments, and course assessments to determine if the goals and objectives are met per the program, but more importantly I conduct relevance assessments to ensure that learners are aware and systematically engaged in the current events that influence the direction of our society. This process is a work that is on a continual Kolb cycle of concrete experience, reflective observation, abstract conceptualization, and active experimentation as reflective practice has no endpoint. Mitigating white invisibility in the adult education program at UDC begins and ends with the Learning Plans that have clear guidelines, are continually evaluated for meaningfulness, builds on prior accomplishments from course goals and objectives that have been successfully achieved, and engages learners in mindfulness of the self as a tool to recognize when their approaches to learning focus on norms constructed by a few rather than the norms of the one seeking to learn.

\section{CONCLUSION}

This paper was intended to discuss white invisibility and how it can be mitigated through intentional reflective practice. In the development of UDC's Adult Education program it is evident that its design encompassed many opportunities for learners to assess and reassess who they are as well as how their identities intersect with their work as Adult Educators. The many assessments in which the learners in this program engage, coupled with the coursework provided multiple chances for intentional reflection. The courses fostered an environment where the learners looked internally and developed insight into who they are as well as how they see themselves. This level of self-assessment juxtaposed with those with whom they interact (currently teaching or will teach in the future). As mentioned previously, the reflection encounters allowed the learners several chances to acknowledge their biases as well as their perceptions. As such, the learners who successfully engaged and completed this program are less likely to perpetuate attributes of white invisibility. Thus, it is less likely for learners from this Adult Education program to think of themselves or any of their learners as "the others;" ultimately mitigating white invisibility. 


\section{RECOMMENDATIONS FOR FURTHER STUDIES}

To further explore and study this topic it is recommended that other programs take similar approaches to what occurred in UDC's Adult Education program. This paper involved a self-assessment and reporting approach to discussing ways to mitigate white invisibility through reflective practice. As mentioned in this paper, having the capacity to develop programs that provide comprehensive learning experiences will not happen automatically. The faculty and program directors must employ intentionality and reflection to achieve such dynamic learning experiences and environments. Therefore, conducting studies, possibly employing the case study methodology would be beneficial in gathering more data as it pertains to this topic. Another potential study would be for programs to consider if "Whiteness" is perpetuated in their programs. Keep in mind that Whiteness, for many Whites, is defined not within a specific race but rather as a nationality. This results in the notion that Whites are solely viewed as Americans; while non-White or "the others" are viewed as only racial subgroups of that American identity (Hartman, 2004). Programs, particularly at institutions that have predominantly white faculty and learners may benefit from looking at their programs and its practices to see where they find themselves on the Whiteness continuum. These programs could use some of the steps used in developing and implementing UDC's Adult Education program. It is essential that programs are developed with the capacity to provide comprehensive learning experiences that take into consideration the individuality of their learners with a desire to increase equitable learning experiences. Mitigating white invisibility is an ongoing process as demonstrated through the development of UDC's Adult Education program. The recommendation for anyone interested in sincerely making their learning environments more inclusive will be to explore this topic with honesty and openness.

\section{REFERENCES}

[1] Sue, D. W. (2006). "The invisible whiteness of being: Whiteness, white supremacy, white privilege, and racism". In Addressing racism: Facilitating cultural competence in mental health and educational settings, Edited by: Constantine, M. and Wing Sue, D. (pp. 15-30). New Jersey: John Wiley \& Sons.

[2] Merriam, S. B., \& Bierema, L. L. 1. (2014). Adult learning: linking theory and practice. First edition. San Francisco: Jossey-Bass.

[3] Thomas, M., Harris, R. \& King-Berry, A. (2016). Creating inclusive online learning environments that build community and enhance learning. In P. Vu, S. Fredrickson \& C. Moore (Eds.), Handbook of Research on Innovative Pedagogies and Technologies for Online Learning in Higher Education. (pp. 304-330). Hershey, PA: IGI Global.

[4] Knowles, E. D., Peng, K. (2005). White selves: Conceptualizing and measuring a dominant group identity. Journal of Personality and Social Psychology, 89, 223-241.

[5] Ware, V., \& Back, L. 2001 Out of Whiteness: color, politics, and culture. Chicago, IL: University of Chicago Press.

[6] Garner, S. 2006 The uses of Whiteness: What sociologists working in Europe can draw from U.S. research on Whiteness. Sociology, 40, 257-275.

[7] Lowery, B. S., Chow, R. M., Knowles, E. D., Unzueta, M. M. (2012). Paying for positive group esteem: How inequity frames affect Whites' responses to redistributive policies. Journal of Personality and Social Psychology, $102,323-336$.

[8] Hartigan, J. 1997 Establishing the fact of Whiteness. American Anthropologist, 99(3), 495-505.

[9] Thomas, M., \& Hilton, A. (2016) "Inclusive Learning Environments: A Focus on Learning Styles, Gender, and Personality Types," Teacher-Scholar: The Journal of the State Comprehensive University: Vol. 7, Article 5. Available at: http://scholars.fhsu.edu/ts/vol7/iss $1 / 5$ 
[10] Charles S. Peirce Society. (2003). Remembering the Gift: W.E.B. Du Bois on the Unconscious and Economic Operations of Racism. Transactions of the Charles S. Peirce Society, 39(2), 205-225.

[11] Biondi, M. (2012). INTRODUCTION.: The Black Revolution on Campus. In Black Revolution on Campus (pp. 1-12). Berkeley; Los Angeles; London: University of California Press. Retrieved from http://www.jstor.org/ stable/10.1525/j.cttlppfmn.4

[12] Kendi, I. (2018). Reigning Assimilationists and Defiant Black Power: The Struggle to Define and Regulate Racist Ideas. In Blain K., Cameron C., \& Farmer A. (Eds.), New Perspectives on the Black Intellectual Tradition (pp. 157-174). EVANSTON, ILLINOIS: Northwestern University Press. Retrieved from http://www.jstor.org/stable/j. ctv7tq4rv.14

[13] Hampton-Garland, P., Cooke, B, and Sechresthardt, L. (2017). Socio-economic and education factors impacting American political systems: Emerging research and opportunities. Hershey, PA: IGI Global

[14] Hartman, A. 2004 The rise and fall of Whiteness studies. Race and Class, 45(2), 22-38.

[15] Kolb, D. A., \& Fry, R. E. (1974). Toward an applied theory of experiential learning. MIT Alfred P. Sloan School of Management.

[16] Bloom, B. S., Engelhart, M. D., Furst, E. J.; Hill, W. H., Krathwohl, D. R. (1956). Taxonomy of educational objectives: The classification of educational goals. Handbook I: Cognitive domain. New York: David McKay Company.

[17] Kolb, D. A. (1984). Experiential learning: Experience as the source of learning and development (Vol. 1). Englewood Cliffs, NJ: Prentice-Hall.

[18] The University of the District of Columbia. (2019). Factsheet udc fall 18. Retrieved from http://docs.udc.edu/irap/ UDC_Factsheet_Fall2018.pdf

[19] U.S. Census Bureau (2017). American Community Survey 1-year estimates. Retrieved from Census Reporter Profile page for Washington DC<http://censusreporter.org/profiles/16000US1150000-washington-dc/>

Citation: Hampton-Garland P, Thomas M, "Mitigating White Invisibility through Intentional Reflective Practice". American Research Journal of Humanities and Social Sciences, vol 6, no. 1, 2020, pp. 1-10.

Copyright (c) 2020 Hampton-Garland P, et al. This is an open access article distributed under the Creative Commons Attribution License, which permits unrestricted use, distribution, and reproduction in any medium, provided the original work is properly cited. 